\title{
Physical properties of hybrid virus nonorganic complexes TMV-Au
}

\author{
Kasiyanenko VKH* and Burdeynyy VM \\ Vinnytsia National Technical University, Ukraine
}

\section{Introduction}

One of the most difficult problems to resolve in nanotechnology is production of nanoobjects with the same geometrical form and size. As some intensive researches show the very promising approach to treat the problem is the use of Tobacco Mosaic Virus (TMV) [1]. The TMV can be chemically and genetically modified in order to alter its physical properties and adapt them to demanded technologic applications. Currently, vast researches directed on the implementation of TMV based methods in the fabrication of nanowires, nanostructured thin films, highly effective microbatteries, solid-state nanoelectronics and biosystems engineering are being carried out in the world. The intensity of these studies is due to the microelectromechanical systems field is more and more developing and allows us to advance in effective miniaturization of functional devices and integrated systems [2-6].

However, some fundamental restrictions of microtechnologies do not permit to ultra pass well-known dimension limits. That is why the integration of nanostructured objects with many functional devices to continue to be a serious problem which is a long way to its complete resolution by conventional methods and materials [7-9].

Tobacco mosaic viruses have a specific structure. It is similar to a nanocabel consisting of hollow protein tubes, inside which the RNA passes. The length of the virus is about $300 \mathrm{~nm}$, its outer diameter is equal to18 nm, while the inner cavity has a diameter of $4 \mathrm{~nm}$. The virus capsid consists of 2130 molecules of protein (monomers), which, like helicoids wrap around the RNA molecule. The protein monomer consists of 158 amino acid residues [10]. It is able to withstand the temperature about $60^{\circ} \mathrm{C}$ during 30 minutes.

Down-up self-assembling is the basic method to synthesize nanodimensional devices. Contemporary synthesis methods allow to realize precise control over the size and shape of nanoparticles produced by applying biomatrix technology. In comparison with semiconductors their fundamental features reveal increasing structural and functional versatility, self-assembly on the surface and predicted controllability of properties. These advantages in combination with the low cost of production predict a revolution in today's technogenic environment.

Modern technology involves biological objects such as DNAs, bacteria, peptides and proteins to create various nanostructures, in particular nanofibers, nanoparticles, and quantum dots. One of the most promising categories of biological nanotemplates which provides exceptional functional opportunities of applications is reduced to plants and bacterial viruses [11-21]. These particles are formed from high-molecular nucleic acid aggregates, consisting of many copies of the protein shell. Above mentioned molecules demonstrate some essenial advantages: they exhibit exceptional stability over a wide range of temperatures and $\mathrm{pH}$-factor values and the ability to withstand influence of denaturation by organic water-soluble mixtures [22].

Between the available viruses, the tobacco mosaic virus is one of the most widely studied filiform structures. The properties of TMV that are extremely useful for nanobiomatrials integration into microsystem devices reduce to well-studied three-dimensional structure, a large amount of bio-physical information on the characteristics of TMV selfassembly on various substrates, discovery of a number of infectious clones from virus of RNA [23-27]. These and other features allow to create new viral structures and surfaces by applying well-studied methods of genetic modification, a expansive quantity of existing exemples of a protein shell with a wide scale of self-assembly properties [28-30]. Beside it possibilities to receive viruses and protein shells from infected plants in an unlimited amount and TMV structural strength make it suitable for use in conventional microelectronics technologies methods [31-35].

The advantages of using TMV's are that all particles of the same type have got identical structure, shape and size; TMV's virions (that is,mature viruses) show capacity to self-assemble and form certain self-organized structures connecting their ends, for example, chains or rings; finnaly they are highly stable both in chemical and physical senses, and also they can be coated with metals, silicon dioxide and semiconductor materials [36-40].

The surface of the virus consists of repeating amino acid chains. The inner cavity consists predominantly of glutamine and aspartic acids, and the outer surface is composed of a large number of lysine and agrinic radicals. This fact is favorable for the virus surface to react with nanoparticles of metals (gold, silver) [37-39,41].

The connection of different nanoparticles with the virus molecule can be controlled during the syntheses by changing the chemical parameters of environment $(\mathrm{pH}$, the presence of oxidizing / reducing agents) [42-44].

\section{Structure, properties and genetic modification of TMV}

The structure of the TMV is stretched on Figure 1. It is an empty tube about $3000 \AA$ in length. The tube has an outer diameter of $180 \AA$ and an inner one of $40 \AA$. The length of the virus core is restricted by the length of decapcided genomic ribonucleic acid (RNA).

${ }^{*}$ Correspondence to: Kasiyanenko VKH, Vinnytsia National Technical University, Khmelnytscke shosse str., 95, Vinnytsia, 21021, Ukraine, E-mail: kasiyanenko.vh@gmail.com

Received: September 11, 2018; Accepted: September 23, 2018; Published: September 27, 2018 


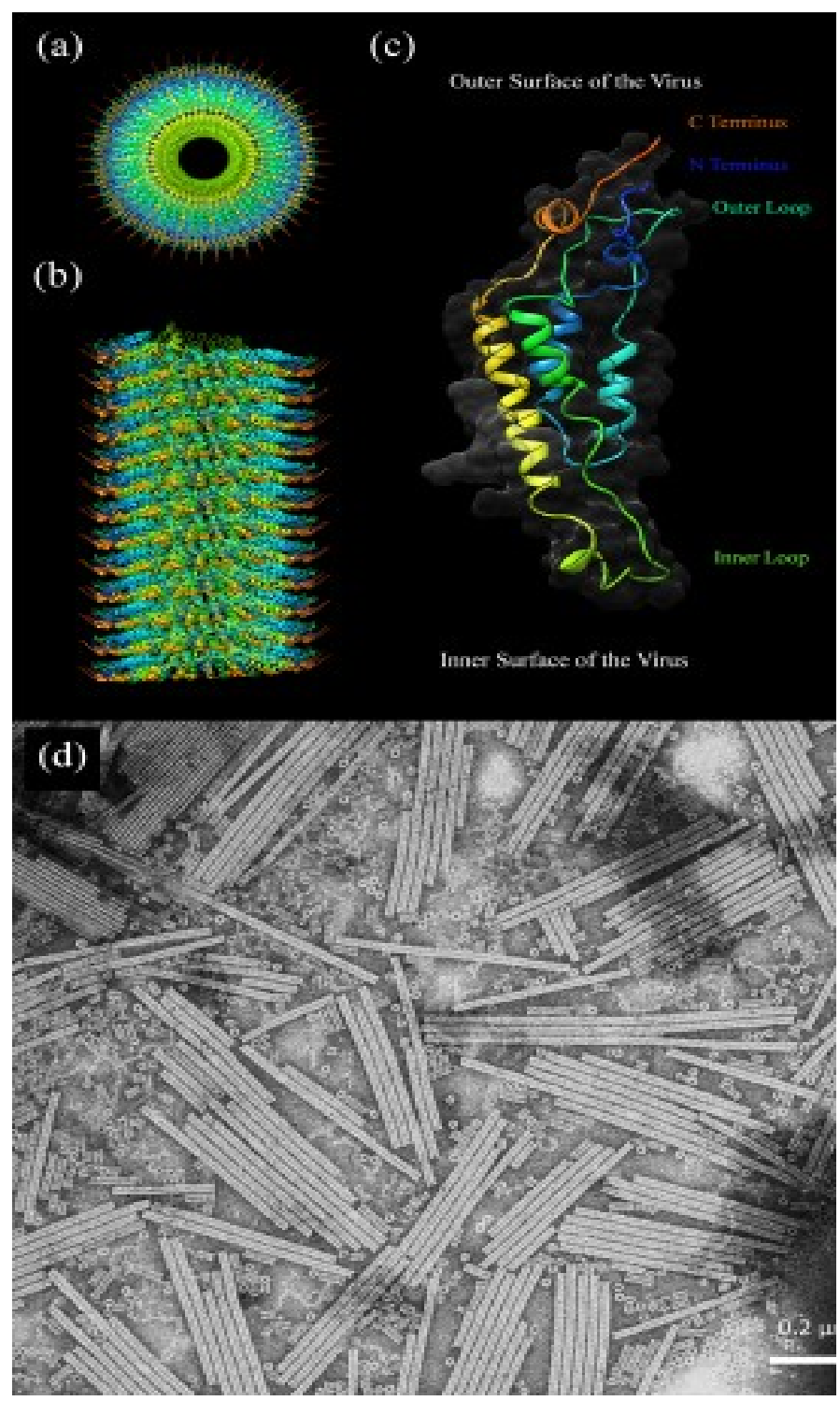

Figure 1. The TMV structure: (a,b) A molecular model showing the front and side view of the VTM virion, (c) A scheme of one protein subunit, (d) TEM image of free type of TMV

The virus capsid consists of 2130 protein molecules (monomers) winding spiral around the strands of RNA. The protein monomer is formed by 158 amino acid residues, which consist of four major alpha helixes composing inner and outer loops [Figure 1 (c)]. The molecular weight of the protein shell unit is $17.5 \mathrm{kDa}$, and this unit forms a helicoide with the step of $23 \AA$ having $161 / 3$ of the protein shell per round. The structure of the VRM virion is determined with a resolution of 2.9 Å by applying X-ray diffraction [24].

Modifications to the protein shell usually occur by adding peptides consisting of 2-20 amino acids, or by replacing the amino acid with the corresponding amine. On the outer surface of the virion, the potential sites for modification are situated on the $\mathrm{N}$ and C-ends (Figures 1 and 2).

The TMV is very strong in relation to mechanical tensions and can withstand heating to $60^{\circ} \mathrm{C}$ for 30 minutes, $\mathrm{pH}$-level about 5-8, and even staying in organic solvents for a long time. Some studies show that the TMV can also withstand more firm conditions. Modified TMVs are generally treated in softer conditions $-0.1 \mathrm{M} \mathrm{pH} 7$ phosphate buffer at room temperature.If exposure to phosphate buffer is undesirable, viruses can be re-suspended or dialysed with deionized water. TMVs and their modifications can usually be retained at $15^{\circ} \mathrm{C}$ for a long period of time. The TMV keep its structure and functionality from a few months to several years under favorable retaining. These peculiarities provide to the TMV significant advantages in front of other constructive biounits for synthesis of microsystems.

\section{Functional coatings based on tobacco mosaic virus and metal nanoparticles}

Nanosized metal particles and metal oxide particles have extraordinary catalytic, electronic and sensory properties. Then manufacture of uniform basic structural elements of nanodevices is vital necessary condition to develop the production of the next generation of microdevices. Synthesis of inorganic materials on the basis of TMV and nanoparticles of metals offers the very promising possibility of manufacturing structures with controllable size, shape and provides stable position at the nanoscale thecnology (Figure 2).

Metal coating: The coverage of TMV by nanomatrixes from different materials is an important stage in integrating nanostructured materials into functional devices. The outer surface and/or the central channel of the TMV can be selectively metallized by chemical deposition. Chemical precipitation is more favorable for biological structures then electrodeposition method due to electroneutrality of biological structures. Beside it, chemical precipitation, as a rule, provides uniform coverage of the entire surface of structures, including nanosized elements. In the first stage, the surface of theTMV particle has to be activated by nanoparticles of noble metal obtained by decomposing of the Pt (II) or Pd (II) complexes. Then, suspension of the TMV is mixed with a solution containing metal ions, complexforming agents, as well as a reducing agent. The deposition is initially catalyzed by noble metallic nanoparticles, and then proceeds as autocatalytic process. Above described scheme allows to achieve the further growth of metal particles.

Selectivity on the inner or outer surface of the coating can be controlled by the presence or absence of phosphate ions in the suspension of TMV [45]. The outer surface of the shell of the
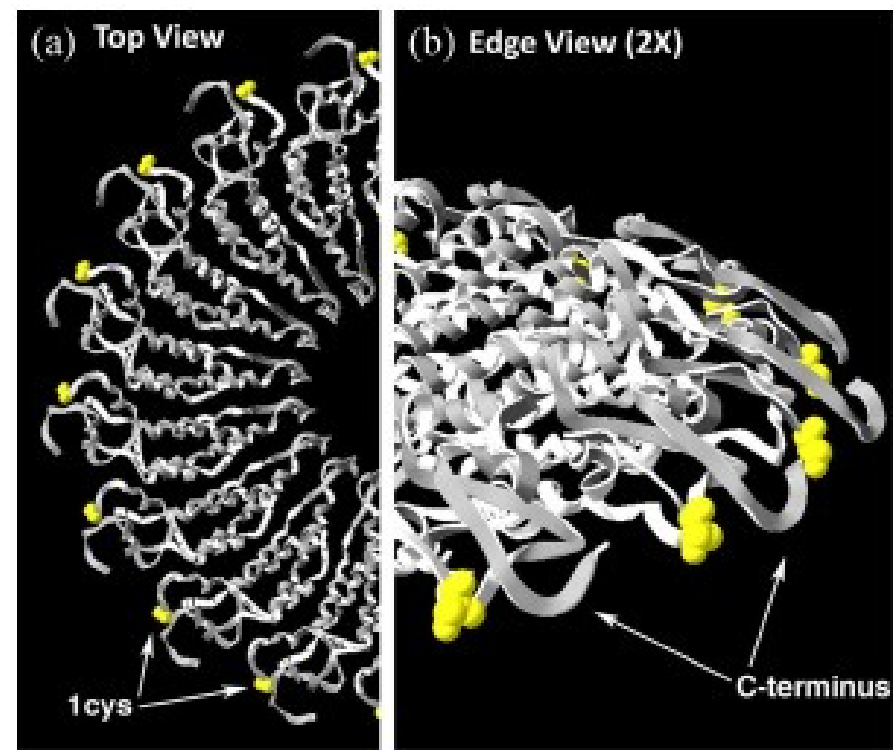

Figure 2. Position of the structure of TMV-1Cys mutation: (a) from the top down a view showing the proteins of the shell of half a turn in the TMV rod and (b) 2 times increase of the same place 
TMVprotein consists predominantly of an oxygen-containing group (e.g., hydroxyl or carboxylic) while within the inner canal amine, primary amine and guanide groups are dominated (Figure 3).

To cover the inner channel with metal, the virions have been dialized before activation and metallization, in order to remove the $\mathrm{Na} / \mathrm{K}$ phosphate buffer. As a result, in the absence of phosphate ions (Figure 3), non-metallic particles form a coating on the outer surface of the virus. In addition, hydrogen bubbles, which are formed during metallization, can prevent the formation of metal clusters on the outer surface of the virus. Metal clusters grow on the inner channel forming metallic nanowires up to $600 \mathrm{~nm}$ in length. Pure metal (Ag, Ni, Co, $\mathrm{Cu}, \mathrm{Pt})$ nanowires and their species consisting of alloys $(\mathrm{Co} / \mathrm{Fe}, \mathrm{Fe} /$ $\mathrm{Pt}, \mathrm{Co} / \mathrm{Pt}$ ) in the diameter of $3-4 \mathrm{~nm}$ were synthesized in the central TMV channel. Nanowire TMV-Ni in the length of about $250 \mathrm{~nm}$ is shown in Figure 3 (b). Silver nanowires can be grown inside genetically modified TMV- E95Q/D109N. For the nanoelectonic applications metal nanowires can be isolated from the biological shell by using endurance in oxygen plasma.
If phosphate ions are presented they attach themselves to the outer surface of the virus, contributing to the selective recovery of metal ions during the stage of surface activation due to the process of chemical deposition. In this case, large metal clusters are formed exclusively on the outer surface of the TMV (Figure 4). If the free TMV for metallization in the presence of phosphate ions is used, deposition of metal clusters of metals on the outer surface of the virus passes without formation of homogeneous films. When suspension of the TMV is treated with $\mathrm{PdCl}_{4}$ and a reducing agent is added, the outer surface of the TMV covered by palladium layer can be obtained. Meantime, the deposition of platinum on the outer surface of the TMV has been achieved if solution contains complex $\mathrm{PtCl}_{6}^{2-}$. The length of the activation step played an important role. For different time of activation, layers of metals with various morphologies (a low quantity of small particles in the background significant number of particles forming a layer) were observed. Coatings of nickel and cobalt, which consisted of large agglomerated particles, are shown in Figure 4 (c) and 4 (e). (a)
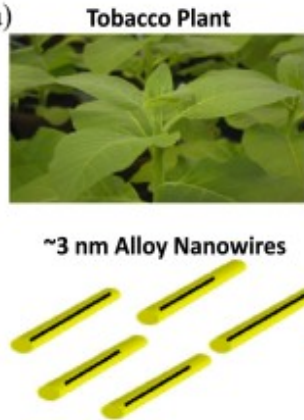

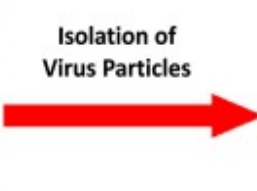

Formation of the metal nanowires in the inner channel of TMV
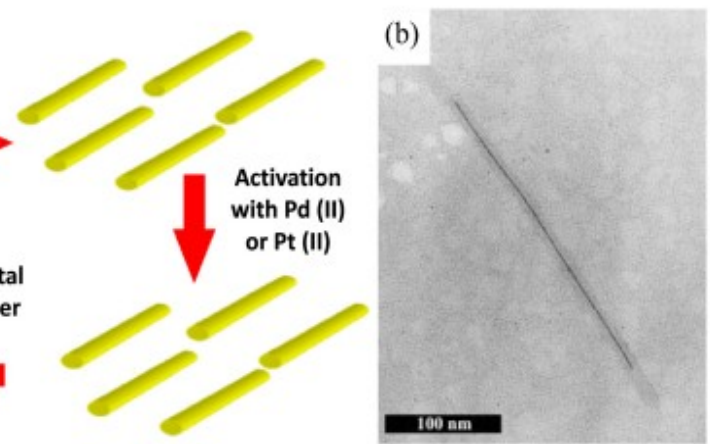

Figure 3. (a) A schematic representation of the synthesis of metallic nanowires in the internal channel of the VTM particles, (b) SEM image of one virion containing inside the inner channel a nickel wire of length about $250 \mathrm{~nm}$ [45]

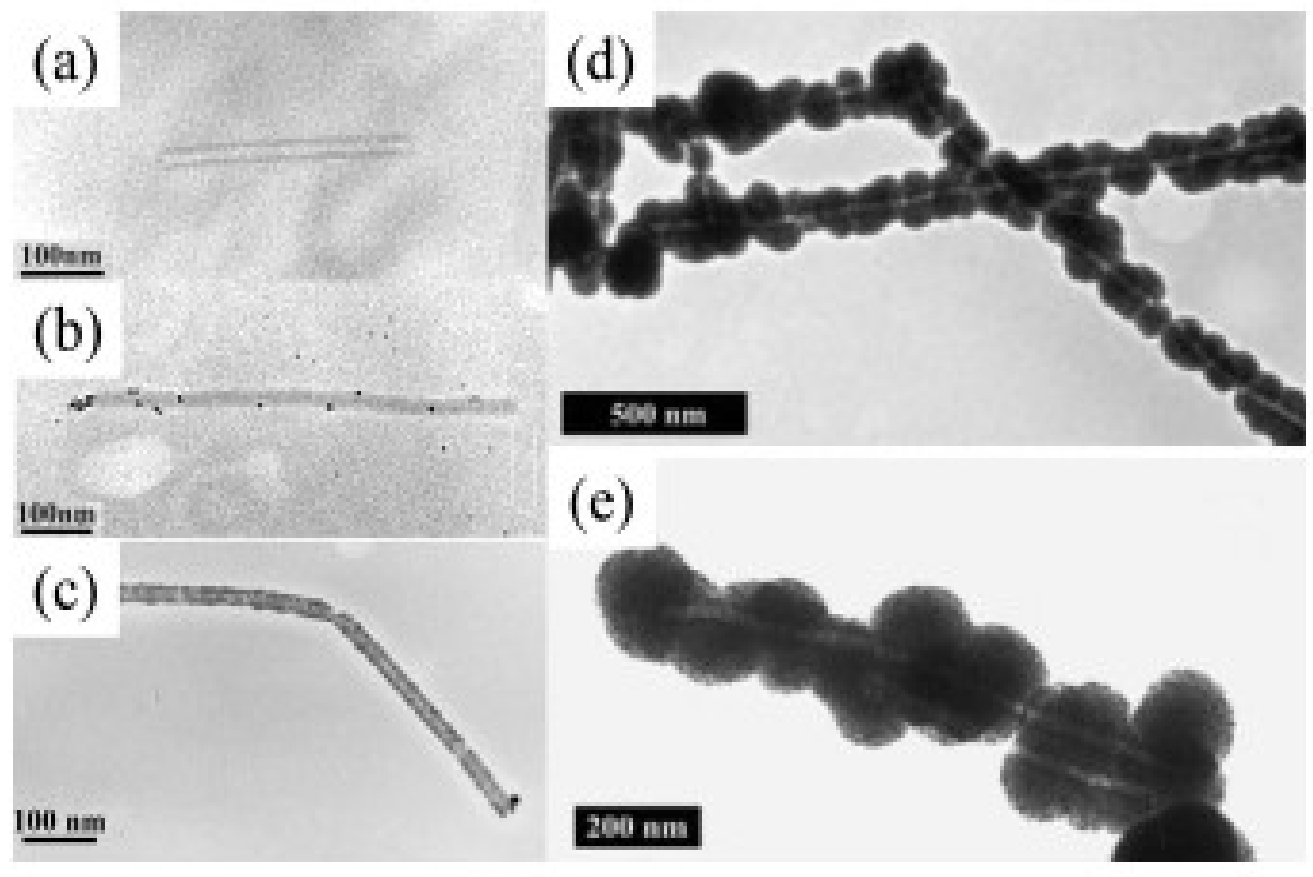

Figure 4. TEM image (a) of the TMV fraction (contours are dark, the protein shell and the central channel are transparent); (b) of the TMV after adsorption (activation) of Pd (II) with subsequent reduction [46]; (c) two TMVs are densely coated with palladium particles; (d, e) Pt (II) -TMV pre-metallized (d) with nickel and (e) cobalt 
The production of micro/nanoscale devices with use of soluble chemical processes and biosupporting materials requires uniform inorganic coatings throughout the surface of biological molecules. However, when the size of the target surface is reduced to a nanometer scale, it is difficult to control the uniformity. As described above, with the use of the free TMV, reduction of metal salt leads to a low efficiency and chaotic appearance of metal virions (Figure 4), due to the emergence of random local formations on the virion surface. The problem of obtaining a uniform and solid coating on the complete surface of the biosubstrat remains a fundamental one in the synthesis of inorganic materials using biosupporting materials.

Modification with Cys-residues containing thiol groups on the surface of the TMV increases the binding ability of the metal. A strong covalent bond between thiol groups and metals makes thiol compounds an effective method for achieving a uniform metallic coating on the surface of the TMV. Mutated TMV-1Cys and TMV-2Cys were used to cover the complex TMV+ $\mathrm{Au}, \mathrm{Ag}, \mathrm{Pd}$, and $\mathrm{Au} / \mathrm{Pd}$. In all cases, there was observed an improved deposition of the metal cluster consisting of the formation more uniform coating than one obtained by using free TMV.

If self-assembly on the surface of gold in genetically modified mutated viruses TMV-1Cys takes place the vertical orientation is dominanted. This self-organization of the virion of TMV-1Cys particle is very promising to use as reliable matrices for the deposition of nickel and cobalt, for the creation of porous 3D metallized networks applying oriented particles of a virus with a metallic coating. Self-organization of the TMV with a golden coating can be provided by keeping the substrates in suspension containing the TMV-1Cys molecules during 1-2 days. After ending it, the surface of the TMV undergoes activation by a palladium catalyst with subsequent reaction of a nickel (or cobalt) chemical precipitation. In this way due to the auto-catalytic nature of the $\mathrm{Ni}$ (or Co) coating, a uniform metallic shell around the TMV can be created. The obtained metal layer is rigid enough to guarantee reliable working with electrodes $[46,47]$.

The coating of zinc oxide on the surface of TMV was first realized by activating of the surface of the virus with Pd (II) and sequential nucleation of $\mathrm{ZnO}$ due to the chemical deposition. The only integral $\mathrm{ZnO}$ nanowires with precisely controlled thickness of coating were synthesized on the TMV particles immobilized on silicon substrates prepared from an aqueous alkaline solution without an activation process. The coating consists of tightly packed spherical polycrystalline $\mathrm{ZnO}$ nanoparticles.

Multilayer coatings: Layer by layer with nanoparticles coating of a surface the creation of special core-shell structure possessing extraordinary properties can be realized. This mentioned multilayer coating on the outer surface of the TMV can be fabricated by using a number of methods. For example, the coating of $\mathrm{SiO}_{2} / \mathrm{Pt}$ was obtained on the free TMV by hydrolysis and reaction of condensation of tetraethyl orthosilicates (TEOS) in an aqueous metal solution at $\mathrm{pH}>7$. It is noteworthy that the viral particles remained stable in an alcohol-water solution (with water concentration $\geq 40 \%$ ), although alcohols usually expose proteins. The reliability of VTM under such hard conditions confirms the promising use of TMV as a matrix for the synthesis of nanostructures.

Platinum metallization was carried out in solution of $\mathrm{K}_{2} \mathrm{PtCl}_{4}$. When $\mathrm{SiO}_{2} / \mathrm{Pt}$-coated particles were formed on the VTM in the TEOS bath, $\mathrm{SiO}_{2}$ was deposited as the second layer, forming then $\mathrm{SiO}_{2} / \mathrm{Pt} /$ $\mathrm{SiO}_{2}$ structure.
The coating of the surface of the TMV with zinc oxide was first made by activating the surface of the virus+Pd (I) and the following nucleation of $\mathrm{ZnO}$ nanoparticles during the chemical deposition. The $\mathrm{ZnO}$ nanowires with reliable controlled thickness coating were synthesized on the TMVs immobilized on silicon substrates from an aqueous alkaline solution without any activation stage applying. The resulting coatings consisted of roughly packed spherical polycrystalline $\mathrm{ZnO}$ nanoparticles have been observed. Comparison of untreated TMV with particles of TMV undergone from one to five deposition cycles (Figures 5 and 6).

\section{Self-assembly, positioning and structuring}

In order to control the assembly process and modeling of the TMV in the functional structure, it is important to learn how to use the exceptional properties of the virus. In spite of the fact that the process of morphology formating and assembling of the virus has been widely and thoroughly investigated, we focus attention on the study of some "unusual" properties of TMV. As it turns out TMVs are universal substrates, which can be geometrically arranged by using of special processing conditions.

First, the nature of the self-assembly of the protein coating of the TMV can be relatively simple changed, in order to obtain demanded new configurations. Beside it TMVs can also be combined with silica and polymers playing the role of substrates and templates for these materials.

Secondly, some of the methods of positioning have already been developed for TMV. In particular, single particles of the TMV can be directly manipulated by atomic force microscopy, although methods for the practically realizable fabrication of TMV templates on large surfaces have only recently begun to be developed. Some of

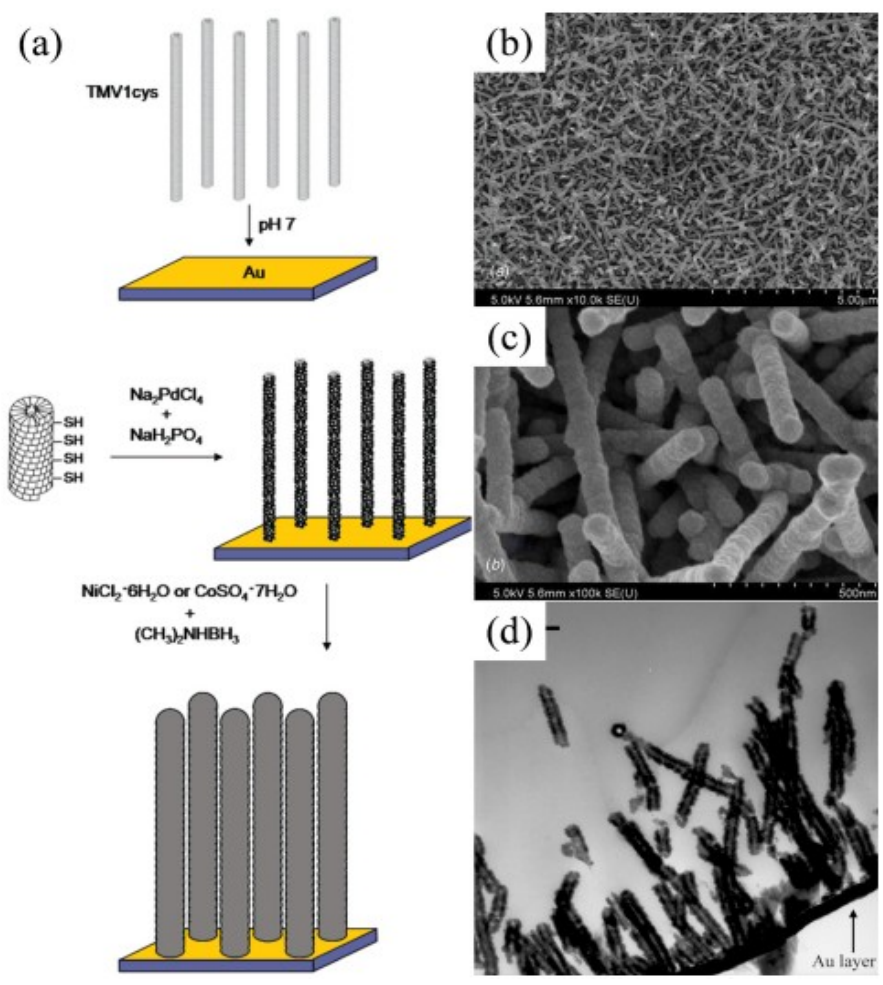

Figure 5. (a) Scheme of assembly of nickel and cobalt coatings on TMV-1Cys attached to the surface of gold. (b, c, d) SEM images of different scales of TMV-Ni self-organized nanostructures [47] 
(a)

\section{TMV1cys surface assembly}

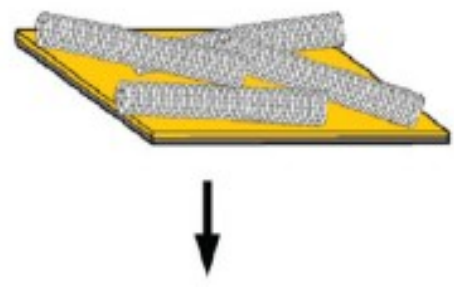

Pd nanoparticle formation with $\mathrm{Na}_{2} \mathrm{PdCl}_{4}$ and $\mathrm{NaPH}_{2} \mathrm{O}_{2}$

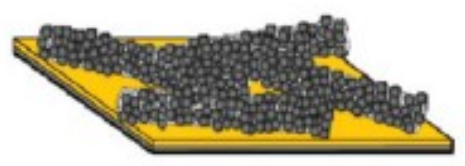

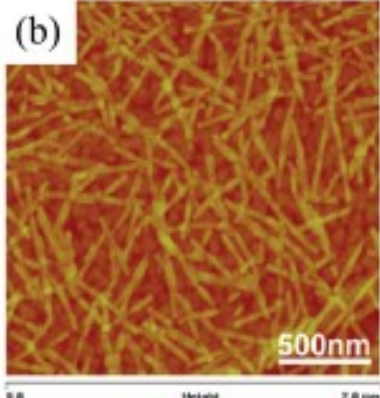

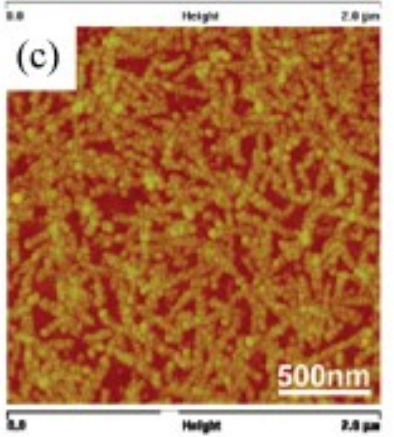

Figure 5a. (a) A schematic sketch representing the TMV-1Cys horizontal assembly on the surface of gold with subsequent metallization of the reducing agent of the precursor $\mathrm{Pd},(\mathrm{b})$ AFM image of the surface of the completed VTM-1Cys on the gold chip, (c) AFM images of Pd nanoparticles, formed on the surface of the assembly of TMV-1Cys [48]
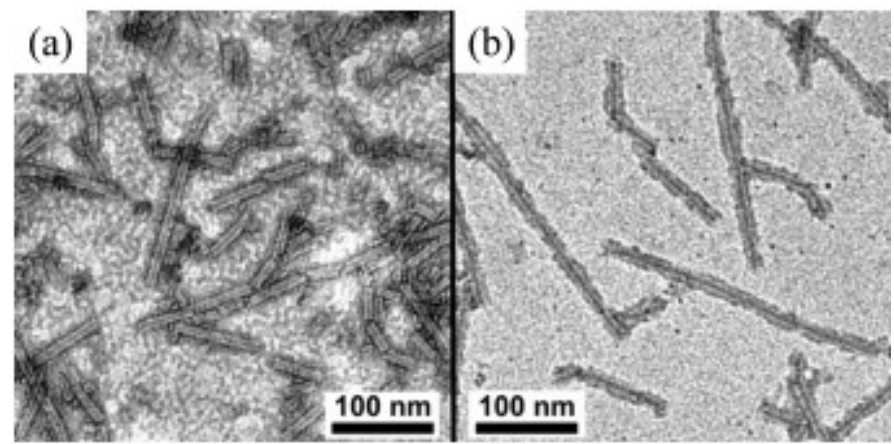

Figure 6. (a)TEM image of the TMV treated by TiO2 ALD. (b) After ultrasonic manufacturing, $\mathrm{TiO} 2$ turns out partially more distant from the outer surface and, in general, the internal channel of the TMV is coated with $\mathrm{TiO} 2$ [49]

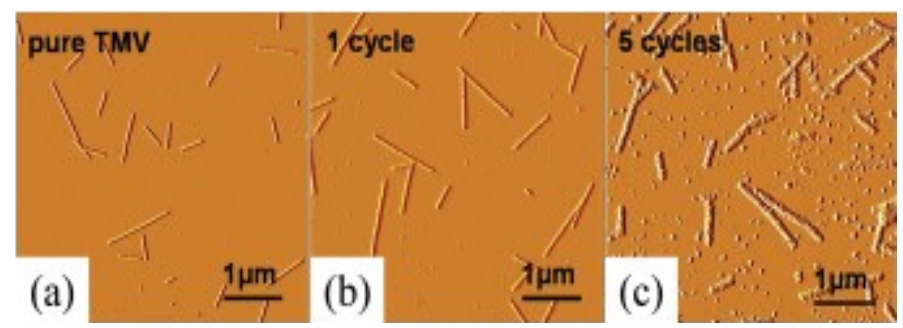

Figure 6a. AFM images amplitude of TMV nanowires, mineralized by $\mathrm{ZnO}$ on silicon substrates. The thickness of the nanowires increases with the number of deposition cycles [50]

these methods, such as convective deposition or stamping, directly control the particles, while others, such as detachment methods and DNA hybridization, control the position by applying special chemical treatment.

Self-assembly: Ensembles of nano-sized rods and discs can be obtained from the proteins of TMV modified with hystidine, by means of the assembly environment controlling. The hexa- histidine (His) tag

is an amino acid that attaches to the $\mathrm{N}$ - or C-ends of proteins and is widely used in the purification of recombinant proteins. When this modified version of the shell protein of the TMV is collected in rods or discs, on the outer surface of the structure remains its residues. That is, by adding HIS-tag to the protein of the shell of the TMV, they can be controlled arranged in fibers, beams, hexagonal lattices, single disks, or vertically-assembled disks (Figure 7). The assembly is controlled by manipulating the concentration of phosphate buffer, $\mathrm{pH}$, and by addition of Ni-NTA (nitrilotriacetic acid) complex or ethanol. It is believed that the concentration of ions influences on the screening of the surface charge of the protein shell and thus the interaction during assembly occurs on the outer surface of the protein layer. On the other hand, $\mathrm{pH}$ affects the assembly of the protein shell in their naturally dominated spiral structures. HIS-tag produces interactions of particles and allows their structural organization. As far as the addition of $\mathrm{Ni}$ NTA complexes to solutions it inhibits this effect.

Directional positioning and structuring: The TMV particles can be oriented with simple processes in the flow of liquid and air. In an aqueous solution TMV particles are guided by drying or removing droplets due to capillary strength applying filter paper. The viruses align in the direction of the fluid flow, more probably because of transverse forces near the surface of the liquid acting.

The air injection method is suitable for surfaces with high TMV interaction, such as high-polar surfaces while the method of lateral absorption of a liquid is suitable for surfaces with weak interaction of TMV, for example, carbon. The characteristic time of diffusion for particles of the TMV from drop to surface is about 1 hour under the concentrations of $0.1 \mathrm{mg} / \mathrm{ml}$. This demonstrates a simple mode of forming an oriented TMV without necessity to create a monolayer or liquid crystal.

A detailed study of the parameters of the convective deposition process of the TMV allowed observing the TMVs with different orientations and thicknesses (Figure 8). During convective deposition, the TMV settles from a suspension and turns out accumulated between the moving layer and the substrate.

The conjunction is formed at the front line of the liquid, drying occurs on the rear edge of objective glass. Roughness of the surface of

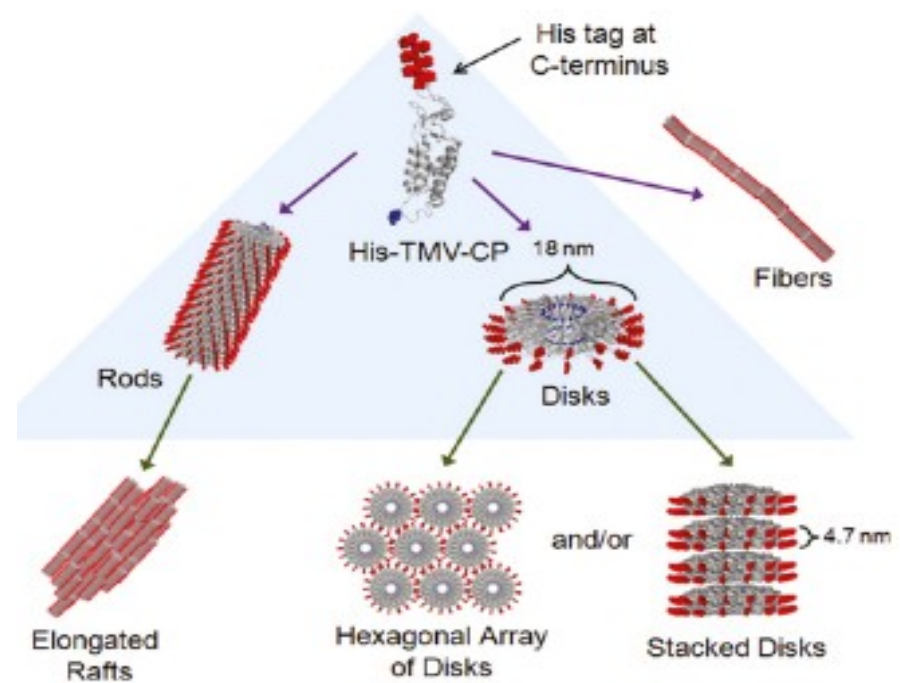

Figure 7. Self-organized structures of TMV (His-tag is shown on the outer part of each protein shell) [51] 

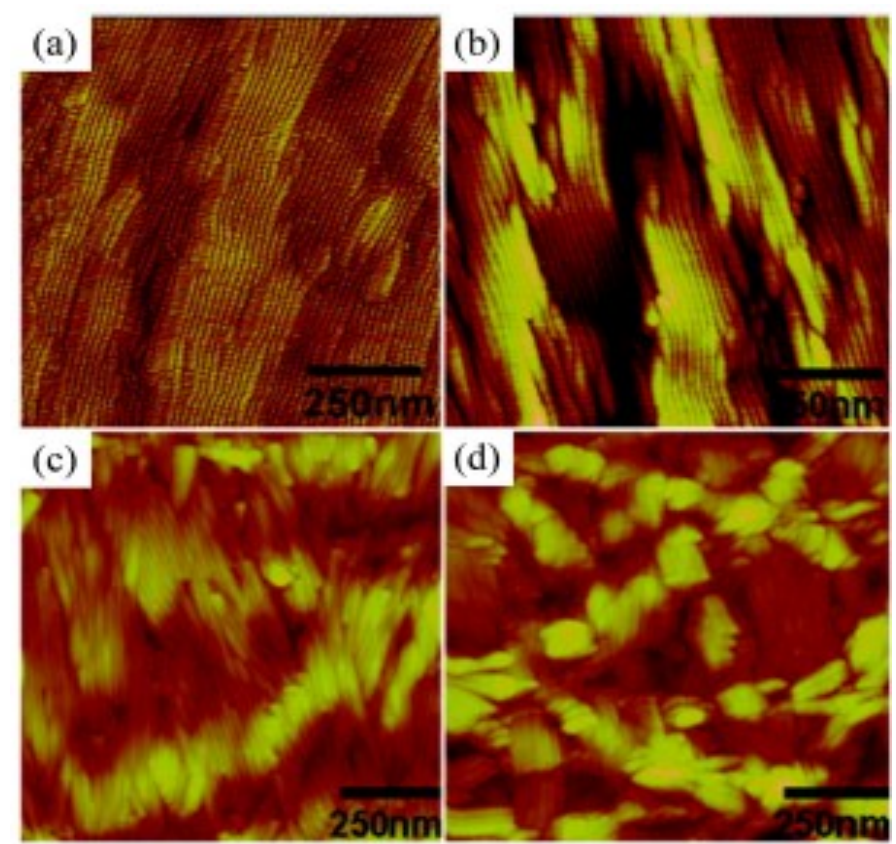

Figure 8. AFM image of the TMV collected on (a) amine, (b) oxide-silicon (c) acryloxy-, and (d) methyl-terminating surfaces. The pictures show a strong dependence of viral ordering on the surface energy of the substrate [52]

the terminal film of TMV is a function of the surface energy of substrate; moreover the increase in surface roughness correlates with an increase in the angle of viscosity of water. The orientation, packing density, and thickness controllable change depending on the concentration of the virus and rate of the assembly. There are four assembly modes: (1) incomplete monolayer with parallel orientation, (2) monolayer with parallel orientation, (3) multilayer with unregulated orientation, and (4) multilayer with anti-parallel orientation.

\section{Application of probing}

Tobacco mosaic viruses have many attractive features that are favorable for use. The TMV is the nanostructure that has a high potential for formation bonds. The ability of TMV to genetic modifications allows them not only to have high selectivity, but also admits to elaborate and create a number of tools for a wide scale of analyses. In addition, its reliability and $\mathrm{pH}$-resistance allow TMV to be easily integrated as a primary receptor in sensory systems. It is also important to mention the use of TMV for chemical and biological probing and their explorations as super miniature platforms in pharmacy and therapy. The TMV is used as a physiological component, namely RNA and protein shells, as a probe for the identification of substances.

Viral RNA can form a skeleton of structure for self-assembly of the protein shell. The same RNA can also be used as a probe. Such probe sensors have been studied and developed due to potential applications for purposes to detect mutations and other applications in gene therapy.

RNA probe and hybridization of DNA: Partial vision disassembly of the viral genome can be realized by adjusting the $\mathrm{pH}$-factor to value $\mathrm{pH}=8$. Yi [33] demonstrated for the first time that the TMV can be modified by complementary DNA probes immobilizing. Fluorescence tomography applies to visualize and describe ensemble of the TMV. The method turns out possible because of existing (establishing)of the thiol marker on the outer surface of the TMV-1Cys. The advantage of marked TMVs over conventional DNA or DNA-probes is the high density of fluorescent markers that can be realized on the surface of the TMV, causing a more powerful fluorescence signal relative to singleDNA hybridization. This study showed the ability of TMM-1Cys to act as a selective probe for DNA hybridization, as well as a fluorescent indicator with improved functional characteristics (Figure 9).

Yi [33] showed that RNA probe of the TMV-1Cys RNA could be improved by using viral nanosubtrates. Using the advantage of partially unprotected RNA in the TMV-1Cys nanosubtrates, the virus can be preliminarily hybridized with a DNA linker. The DNA linker acts as an addition to the open TMV-1Cys RNA in the first half of the linker. The other half is programmed to capture a sequence of DNA probes that turns out selectively immobilized on the surface of the crystal (Figure 10). Completely hybridized TMV-1Cys can execute self-assembles into address DNA probes. By observing fluorescence different in color one is able to distinguish these two differently programmed types of DNA linkers.

Different platforms were implemented to have a greater variety of programmed DNA sequences without introducing additional fluorescent differentiation of markers. The above pointed work showed the ability of TMV to complete integration into very promising detectors.

Detection by modifying shell protein: The RNA of TMV is the main element where hybridization of the DNA takes place. The outer surface of the TMV protein shell has thousands of points that can be suitable to form selective binding. Brakman and al. chemically realized functional activity of the free TMV with oligoaniline (TMV:OANI) in order to be able to detect volatile organic compounds (VOCs). The resistance was determined by two-electrode scheme with measuring of change in conductivity through the layer of TMV:OAN1 receptors. Experiments have shown that TMV: OANI has high selectivity in relation to ethanol and methanol.

The protein layer also showed a large number of bonds on the outer surface, including the sequence of the oligopeptide. Short sequences of peptides are particularly interesting due to their notable potential for high affinity and selectivity. To date this feature lies in the base of the method suitable to identify numerous single-chain antibodies, as well as peptide receptors that bind to significant quantities of pathogens and toxins. Flexibility and remarkable ability to integration are two important factors in the development of reliable and highly sensitive universal probing systems. The reliability of the architecture and genetic manageability of the TMV makes it an extremely flexible platform for controlled detection of peptide receptors on different substrates.

Beside it as a detecting substance in electrochemical sensor TMVTNT (trinitrotoluene) is often used. Peak current shows a linear dependence on the concentration of TNT in the system. With the addition of TMV-TNT to the TNT solution was observed that current drop turns out lesser then it was established for pure solution (Figure 11). This effect can be explained by the TNT bonds with peptide. As a result, TNT molecules mobility reduces that causes a decrease in the current drop. The difference in peak current for unchanged TMV and modified combination, namely contained TMV-TNT, appeares and increases achieving saturated value of $4.5 \mu \mathrm{A}$ ( $46 \%$ of absolute peak current compared to controlled) beginning from a TNT concentration of $4.3 \mu \mathrm{g} / \mathrm{ml}$. Exactly this current difference can be proposed to detect TNT included substances. 

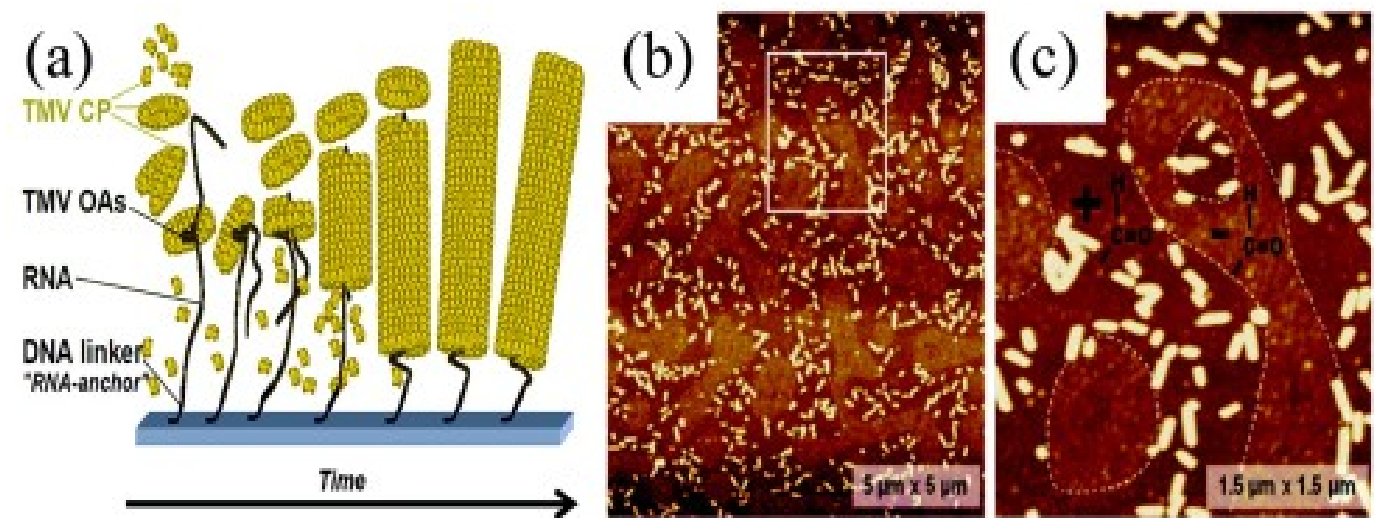

Figure 9. (a) Sketch of the RNA-directed assembly, (b) AFM image of the relief of the rods of the TMV CP, (c) Close-up [53]
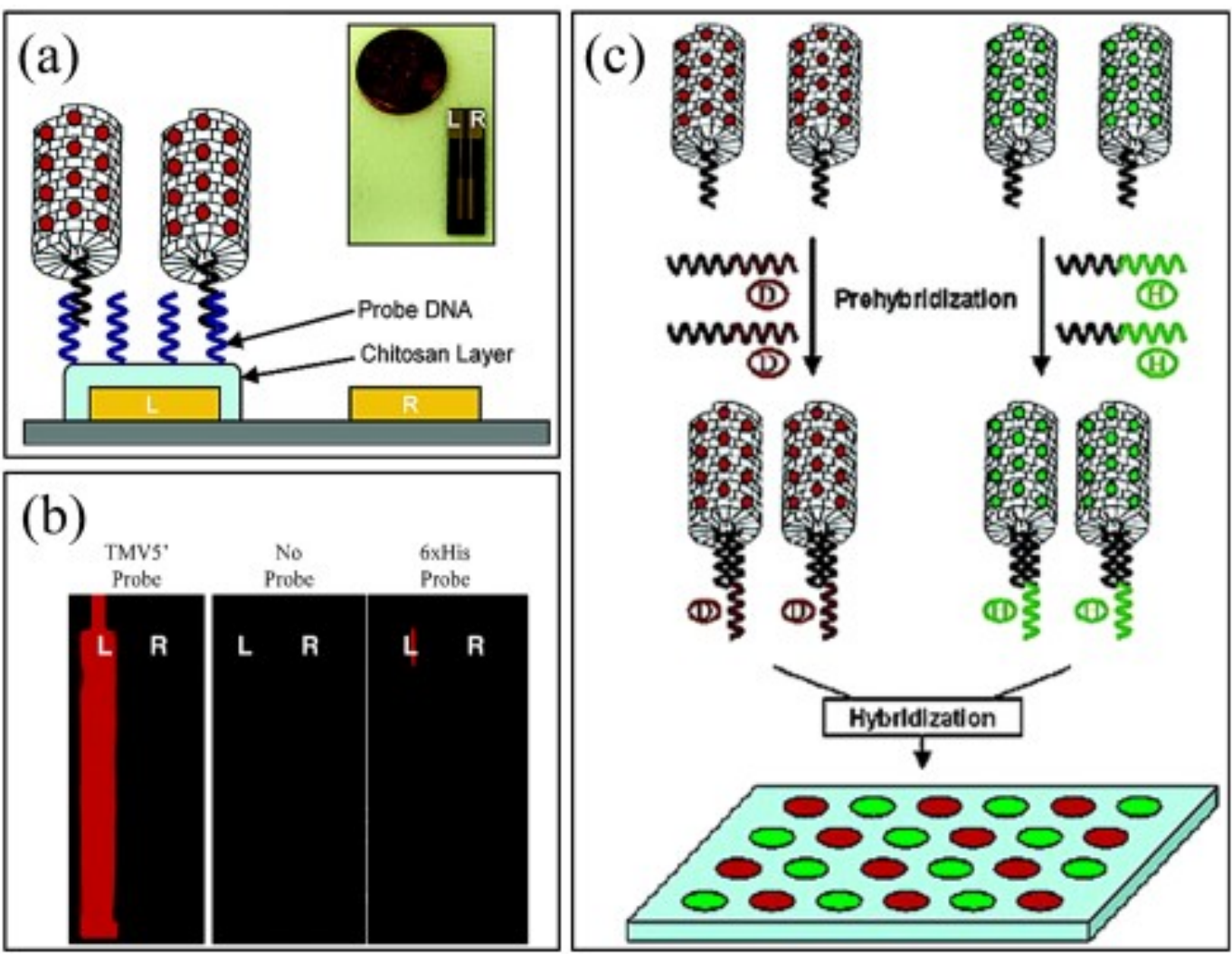

(b)

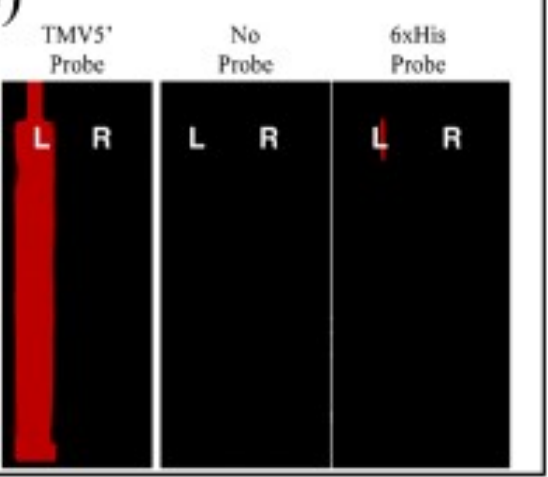

Figure 10. (a) RNA is selectively hybridized with DNA, (c) luminescent images, (b) a diagram of hybridization

Investigation of optical properties of vtm-nanoparticipants of black-goat metals

The method of obtaining silver hydrosoles is based on the restoration of silver nitrate by tannin in the presence of a buffer solution of sodium tetraborate and sodium hydroxide $(\mathrm{pH}=9.8)$. In the reaction volume containing the buffer solution $(\mathrm{pH}=9,8)$ the tannin solution was added under the room temperature. Then the solution of $\mathrm{AgNO}_{3}$ undergoing to uninterrupted stirring was introduced at a rate of $1.3 \mathrm{ml} /$ min. For the synthesis water solutions of silver nitrate and tannin with following compositions of agents were used: 1) with equimolar ratios, 2) with the excess of tannin ten times, and 3) with the tenfold excess of silver nitrate. The Figure 12 shows optical spectra of soles which were situated in quartz cuvettes. The optical path length was of $10 \mathrm{~mm}$ and the wavelength interval was about $350-600 \mathrm{~nm}$. On the curves the formation of plateau can be observed. If the excess of silver takes place clearly distinguished band at $\lambda=420 \mathrm{~nm}$ can be detected too.

Characteristics of soles demonstrate certain level of sensibility in relation to proprieties of solvent. In order to verify this suggestion the effect of solvent type on optic parameters of soles the synthesis of nanosized silver particles was carried out with using of $96 \%$ ethanol solution. The maximum of optical absorption band in ethanol turns out shifted to the long wave part in comparison with the hydrosol optical spectrum (Figure 13).

The study of the obtained nanowires was carried out in the ultraviolet and visible interval of wavelengths on the two-beam spectrophotometer SPEKOL One only maximum at $540 \mathrm{~nm}$ has been 


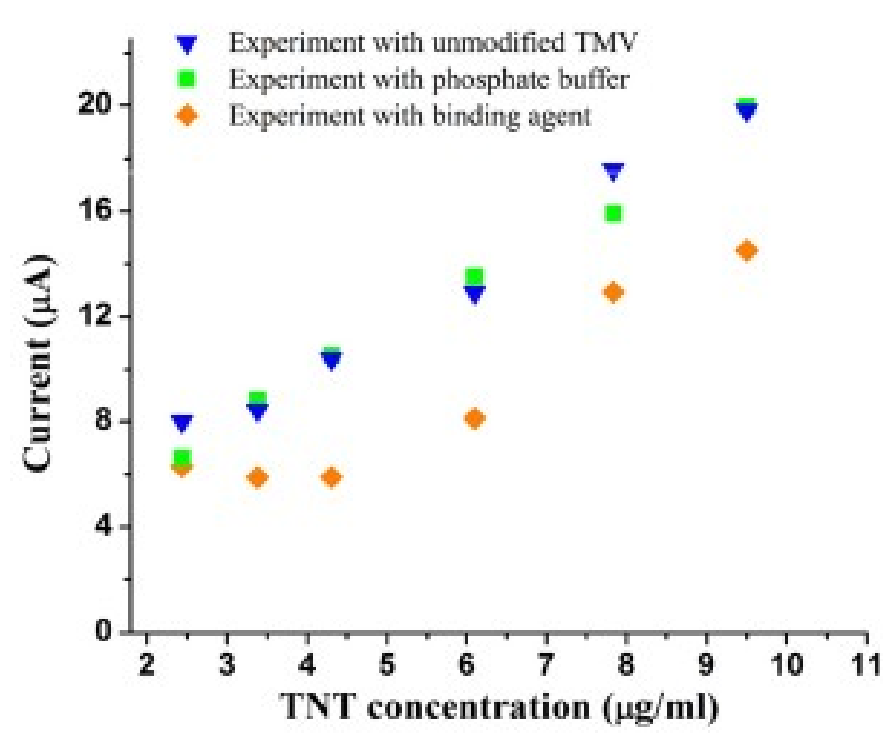

Figure 11. Peak currents of reduction of TNT using phosphate buffer, the unmodified TMV and TMV-TNT-PB binding agent

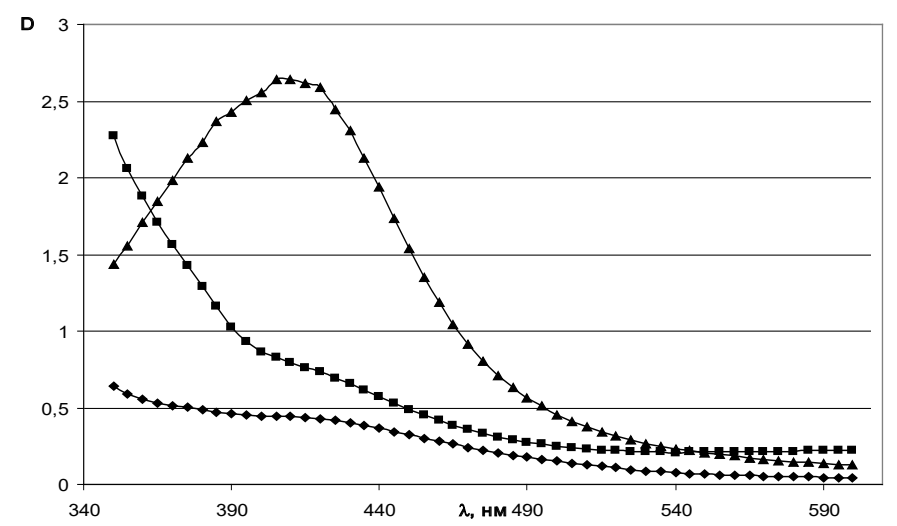

Figure 12. Optical spectra of silver hydrosoles, obtained: $\downarrow$ - in equimolar ratios of silver nitrate and tannin; $\mathbf{-}$ - more than tannin; $\boldsymbol{\Delta}$ - in excess of silver

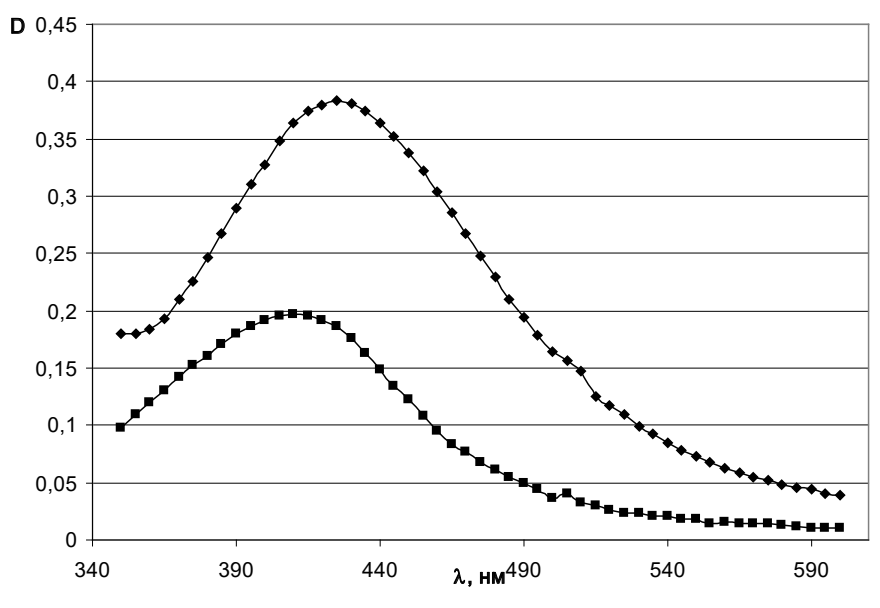

Figure 13. Optical spectra: - silver sol in ethanol; - - silver hydrosol

observed on the graphs of the optical density of nanowires dependence on wavelength. This fact doubtless points out on the optical activity of the nanowires in this wavelength segment. It should be important to sub line that there are no peaks of absorption for pure viruses (Figure 14).
The our results clearly indicate on existing of optical anisotropy and they have been confirmed by the data of work [48-53]. The TMV is a rod-shaped virus consisting of a right screw single-breasted ribonucleic acid and demonstrate a positive peak in the spectrum of circular dichroism (CD) at $190 \mathrm{~nm}$ and a negative peak at $209 \mathrm{~nm}$ due to excitation and the transition from $\pi$ to $\pi^{*}$ with optical dipoles perpendicular to axis and parallel to the same axis respectively [53].

On the CD spectra peaks correspond to gold nanoparticles in the wavelength interval of 200-300 $\mathrm{nm}$ are not observed. Concerning the TMV-Au complex there is a negative peak of the CD at $222 \mathrm{~nm}$ and a maximum of $540 \mathrm{~nm}$ on the optical spectra. This fact can be interpreted as manifestation of the correlation between circular dichroism and plasmon resonance spectra of TMV-Au and the correlation of plasmon resonance and optical activity, as well as the presence of two types of chiral structures in the TMV-Au complex: right amino acids, and right a-helix consisting of the amino acids. Thus the TMV-Au admits to be treated as a chiral medium in which the refractive index for right and left-hand polarization in the direction of propagation $+\mathrm{x}$ is $\mathrm{n}+$; $\mathrm{n}$-, respectively. Given that the refractive index depends on the direction of propagation these indexes for the right-hand (left-hand) polarized light in the direction - $\mathrm{x}$, were designated respectively as $\mathrm{n}+(\mathrm{n}-)$. The established difference in the refractive index plays a significant role in interpreting of the obtained, namely, the chiral medium can be refered to the normal medium with the refractive index $n$. The length of the normal and chiral component of the medium 1 and L-1, respectively. The ratio of the transmission coefficient for the right-hand polarization $t+$ and the left-hand polarization $t-$ is determined by the method of transfer matrices. Then the ratio $t-/ t+$ can be expressed as

$$
\frac{t_{-}}{t_{+}}=e^{-2 i\left(\theta_{+}-\theta_{-}\right)} \times \frac{A_{+-}}{A_{-+}}
$$

where

$A_{+-}=\left(\cos \theta-\frac{i}{n} \sin \theta\right) \times\left[n_{+} e^{i \alpha_{+-}}+n_{-} e^{-i \alpha_{-+}}+n_{+} n_{-}\left(e^{i \alpha_{+-}}-e^{-i \alpha_{-+}}\right)\right]$ $+(\cos \theta-n i \sin \theta) \times\left(e^{i \alpha_{+-}}-e^{i \alpha_{-+}}+n_{-} e^{i \alpha_{+-}}+n_{+} e^{-i \alpha_{-+}}\right)$

and

$$
\theta=k l / n, \theta_{+,-}=k l / n_{+,-} \alpha_{+-}=k l / n_{+}-k L / n_{-} .
$$

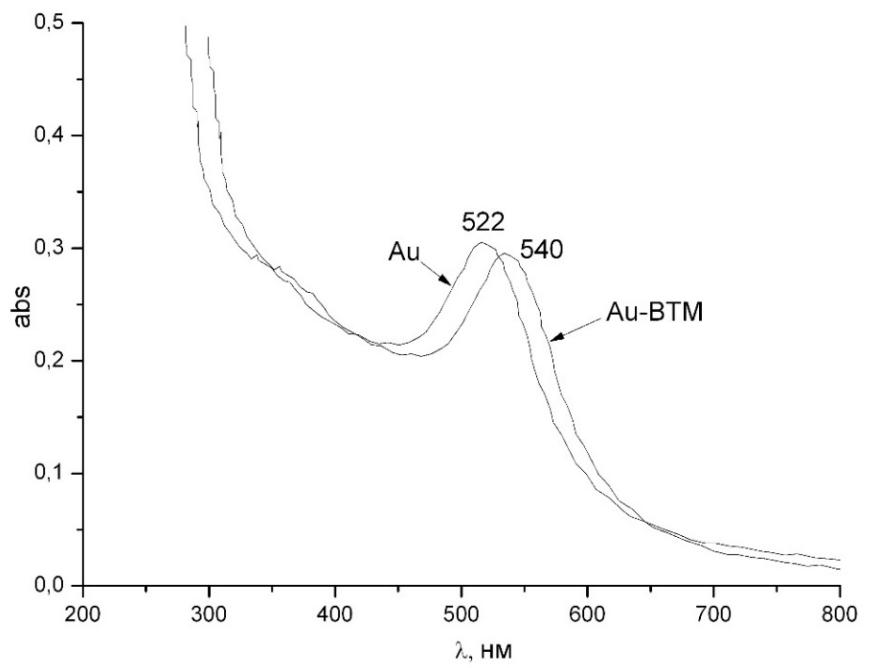

Figure 14. Optical spectra of pure nanoparticles and nanowires TMV-Au 
The first factor of the right-hand side of the equation (1), that is $e^{-2 i\left(\theta_{+}-\theta_{-}\right)}$gives an optical activity without the influence of the normal medium. The second one, that is $A_{+-} / A_{-+}$corresponds to the effect of connecting the normal segment to the chiral part of the system, and it is responsible for the optical activity $A_{+-} / A_{-+} \neq 1$. This term describes the modification of optical activity. The plasmon frequency $A_{+-} / A_{-+}$ has got significantly high value due to plasmon resonance leading to a notable increase in optical activity. On the other hand, in the UV region, $A_{+-} / A_{-+} \sim 1$. Therefore the optical activity of the complex is increasing too. Thus the optical activity of the complex in the UV region is not less than that of the chiral medium. This simple model provides a consistent explanation of the experimental results and opens up the possibility of using the TMV-Au complexes to create 3D metamaterials.

\section{Investigation of electronic properties of TMV-Au nanowires}

The method of probe tunneling microscopy and spectroscopy was applied to study the electronic properties of viruses and nanocomposites based on the TMV and gold nanoparticles. Experiments were carried out on the JEOL equipment (JEOL 4500).

The investigation of the electronic properties of the synthesized nanowires (Figure 15) allowed establishing that during the scanning from 0 to 6 Volts, spontaneous and induced transitions to a state with relatively high electrical conductivity arise. It is interesting to sub line that for pure TMV the effect has not been observed.

The current-tension characteristics of the TMV-Au nanowires show a abrupt jump when a voltage of $3.1 \mathrm{~V}$ is applied with a subsequent stabilization in a new value (Figure 16). Before reaching the voltage 3.1 $\mathrm{V}$ the current is gradually increasing. When the voltage decreases to $-2.4 \mathrm{~V}$, the system returns to the initial state (Figure 16).

The observed effect of "conductivity switching" in the nearest future can be used to create digital recording devices with high density information to record. The principle of such a device will be based on the transfer of charge from the shell of the virus to the nanoparticle when the external electric field is applied. Every of such TMV-Au hybrid unit can work as an energy-independent storage device, and its conductivity can be switched between high and low values identified as logical "zero" and "unit". However, it is necessary to find a suitable substrate allowing to stabilize the accumulated charge in order to save the information, that has been recorded (Figure 17).

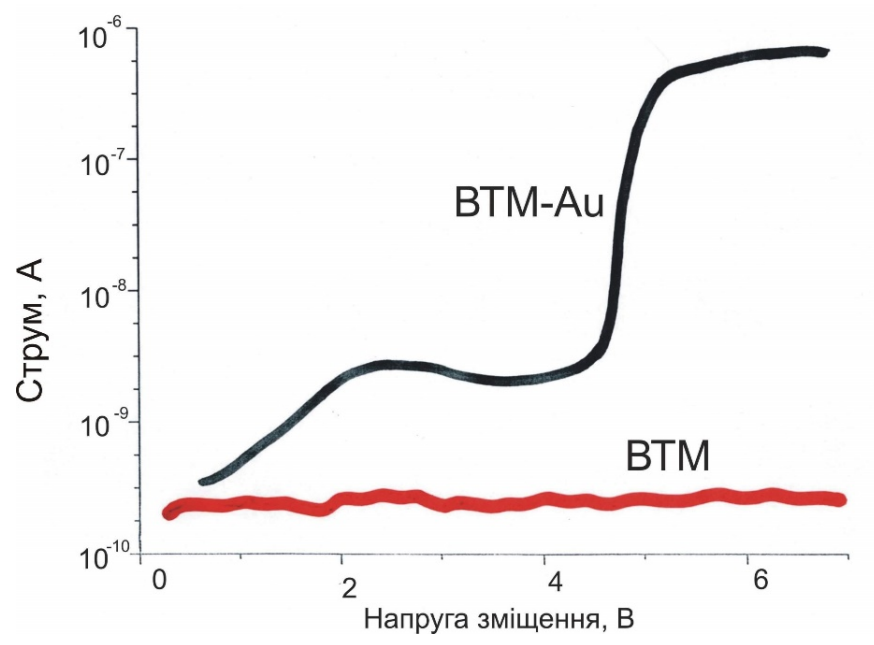

Figure 15. The current-tension characteristics (I-V) for the nanotube TMV-Au and pure TMV

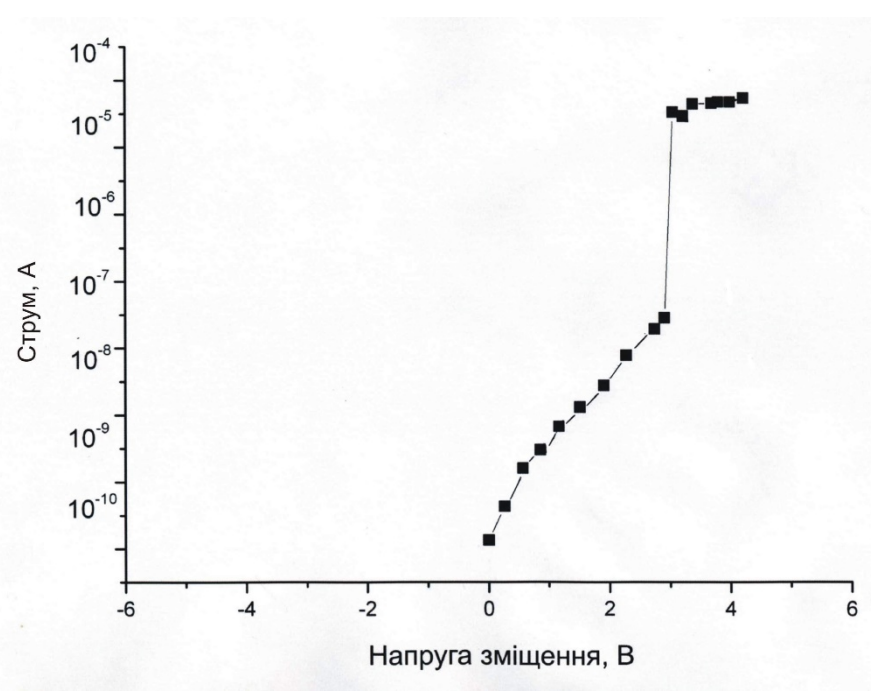

Figure 16. The current-tension characteristics of the TMV-Au

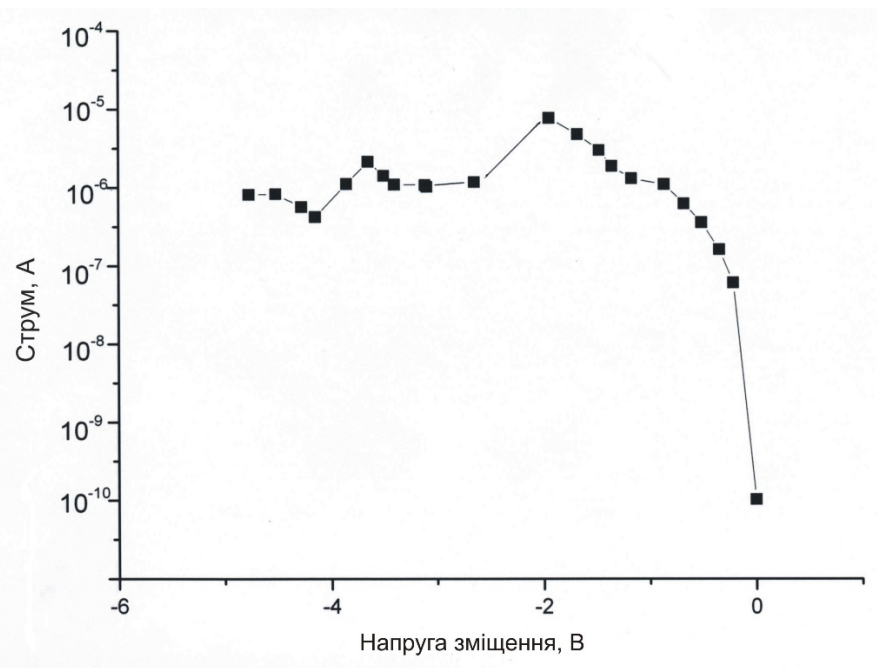

Figure 17. Current-tension characteristics of the TMV-Au nanowires

\section{Investigation of adhesive and oxidizing properties of tmv viryon on the surface of silicone crystal}

The adhesion properties of a tobacco mosaic virus on the surface of silicon spraying with gold were investigated by atomic force microscopy. A continuous coating of the surface of the TMV by gold nanoparticles was established. These nanoparticles of gold, unlike ones obtained by chemical synthesis, are localized near the viruses, mostly in the ends of the viruses and less often at their edges. The height of the synthesized wires, determined on the base of the received images, was $10.5 \pm 0.9 \mathrm{~nm}$, which, within the measurement error, correlates quite well with the value of the TMV particles diameter evaluated by other methods (Figure 18).

The presence of particles whose length is nearly two times larger then the length corresponds to the maximum $(300 \mathrm{~nm})$ was observed. This fact indicates the ability of the virions to form "face to face" bindings. If the increase of the concentration of TMV takes place beside of the "face to face" junction an aggregation of "side-to-side" viral particles is also detected with participation about dozen particles in such interaction (Figure 19). 


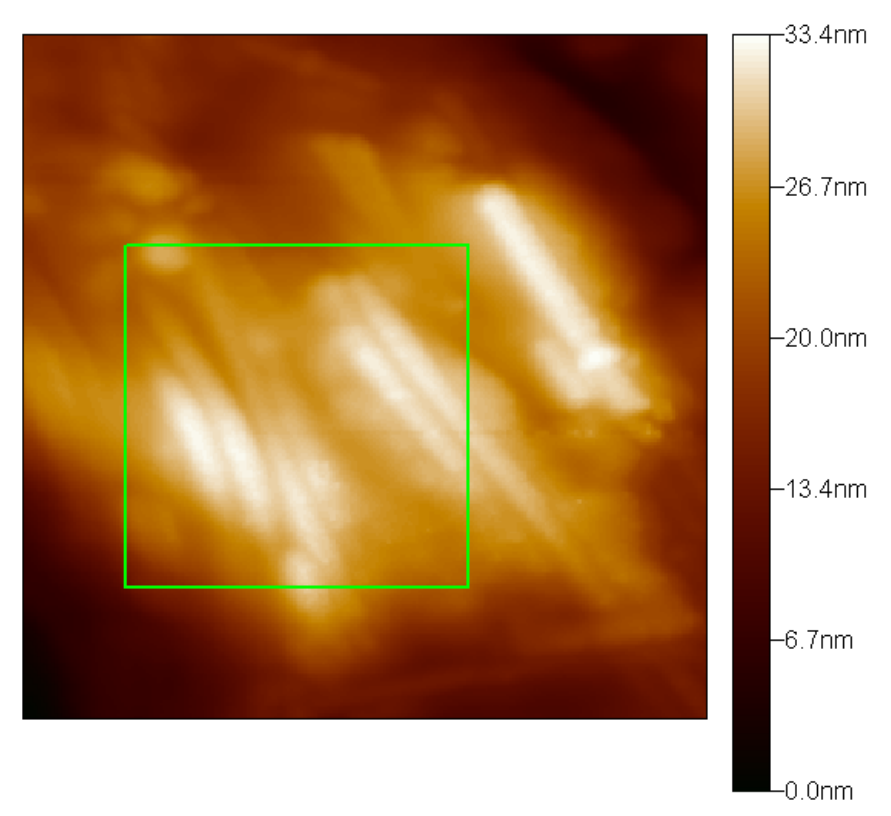

Figure 18. AFM image of TMV-Au nanowires on the (111) surface of Si monocrystal

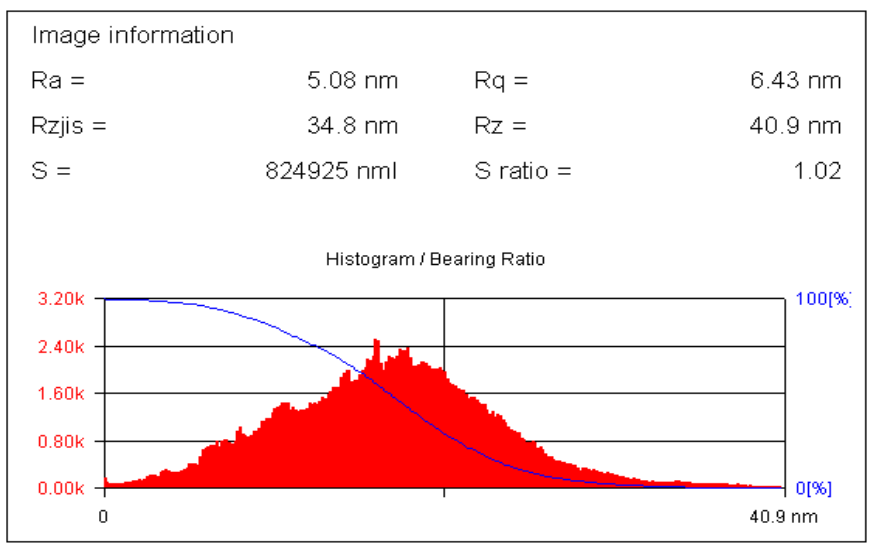

Figure 19. Distribution of dominated location of nanowires in green squares of Figure 18

Appearance of aggregates in the form of islands on the silicon substrate gives ground reasons to suppose that some cooperative mechanism of binding among virus particles has to exist. As it was established, a preferred direction in the orientation of TMV particles on the surface of silicon repeats the direction of the silicon crystallographic axes.

For nanowires obtained by application of the method of the thermal deposition of gold the strength of binding of viruses to the surface of metals and semiconductors was determined with using atomic force microscopy.

After removing TMV from the surface of gold, a study of morphology of surface by atomic force microscopy was performed. The carried out investigations showed a significant change in the relief of gold (Figure 20).

The depth of formed cavity reached $2 \mathrm{~nm}$, and its width was about $18 \mathrm{~nm}$, These date suggest that discussed cavities were created by viruses (Figure 20). The sub lined result is of great interest because of well known low level of passivation of gold. There are several assumptions about the nature of the interactions of virions with gold. Concerning the nature of interaction between virions and gold surface one can choose from two types, namely, a physical adsorption or chemical one. Physical adsorption is the result of van der Waals forces action and reduces to creation of hydrogen and other electrostatic bonds. As far the chemical adsorption it occurs due to chemical interactions between substances.

The presence of characteristic grooves produced by virions indicates a high chemical activity of TMV virions (Figure 21) and points out on the chemical adsorption as dominated type of interaction.

\section{Behavior of TMV and AMV virus in interaction with antbodies}

The viruses consist of nucleic acid and globular protein molecules and are the simplest forms of living organisms. The viral particle does not have its own reproduction tools, however, penetrating into the cell, provides its own replication due to the synthesis of viral proteins by infected cell. The size of the viral particles varies from 15 to $1200 \mathrm{~nm}$. In addition to their biological features (reproductive ability, infectivity, contaminative intensity), viruses have a lot of other properties. In particular, viral particles can form periodical structures with useful optical properties. The presence of a large number of charges on the internal and external surfaces of the virions allows producing nanoparticles by applying the biomimetic method. The ability of viruses to penetrate inside the cell can be used to create the most progressive intracellular nanoprobes and nanosensors. The most promising applications in nanotechnology are plant viruses, since they are safe for humans and animals and can be obtained in large quantities and can withstand various modifications.

To investigate the behavior of rod-liked viruses with helical symmetry of their protein subunits, in particular, tobacco mosaic virus and alfalfa mosaic virus (AMV), a high-resolution probing microscopy method was used.

TMV suspensions at a concentration of $12 \mathrm{mg} / \mathrm{ml}$ and AMV at a concentration of $10 \mathrm{mg} / \mathrm{ml}$ were used. The suspensions were deposited
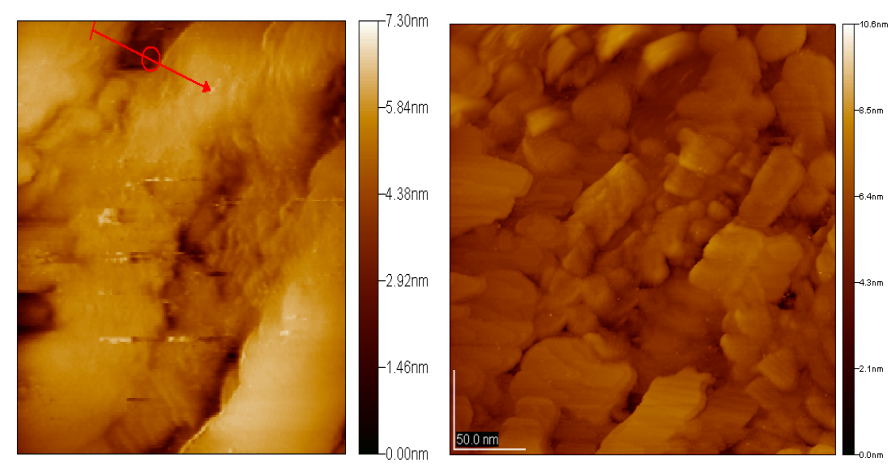

Figure 20. The image of the surface of gold after removing of the TMV

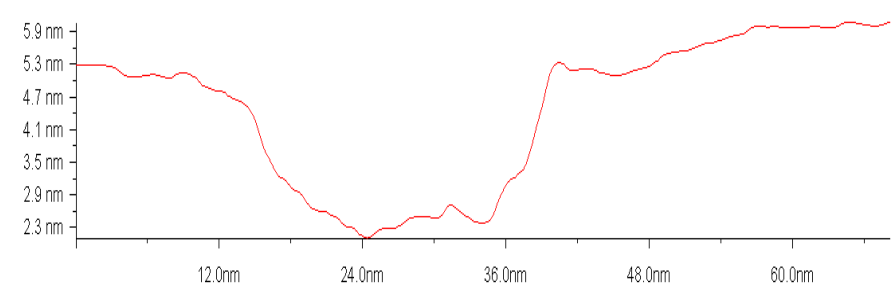

Figure 21. Characteristic profile of cross section of the cavity on gold surface after the virions of the TMV was taken off 
on the surface (111) of a silicon monocrystal by applying a microsyringe. After drying of the Si (111) surface into a streaming beam of dry nitrogen the sample was put in the atomic force microscope (AFM) working chamber. The residual pressure in the chamber of probing was $3.0 \times 10^{-8} \mathrm{~Pa}$. For the surface exploring cantileveres fabricated from nitride of silicon, that is $\mathrm{Si}_{3} \mathrm{~N}_{4}$, have been used. The study of the virus on the surface of a monocrystal was carried out in a contactless AFM mode with atomic resolution.

During the experiment, the interaction of TMV with the surface of Si (111) was investigated for two different conditions. The first corresponds to the fresh virus suspension and the other one referred to the suspension taken 4 months after it has been prepared. The obtained results were compared with ones corresponding to the study of the AMV interaction with identical surface.

The most significant problem reduces to mechanism counteracting to the virion aggregation. In attempt to resolve the problem, we have investigated the behavior of viruses on the surfaces of a silicon monocrystal with the preliminary vaccination them with antibodies. Figure 22 shows the behavior of AMV viruses on the (111) silicon monocrystal surface.

The application of a suspension of AMV virions to the (111) surface of $\mathrm{Si}$ (111) was accompanied by the aggregation of virions in dense aglomerations and a decrease in height of obtained clusters from $19 \mathrm{~nm}$ to $9 \mathrm{~nm}$. In this case, the formation of multilayer disordered clusters of virions was predominantly observed (Figure 22).

There are two types of adsorption: 1) physical - occurs due to dispersion (Van der Waals) forces, the formation of hydrogen and other electrostatic interactions; 2) chemical - due to the formation of chemical bonds between adsorbate and adsorbent. As is known, the outer and inner surfaces of the virus capsid due to the presence of positively and negatively charged groups in the composition of the amino acid side radicals, carry charges of the opposite signs. However, the(111) surface of silicon has no charge. Therefore interaction of a capsid with this surface can not be related to electrostatic attraction. Consequently the electrostatic nature of such interactions has to be

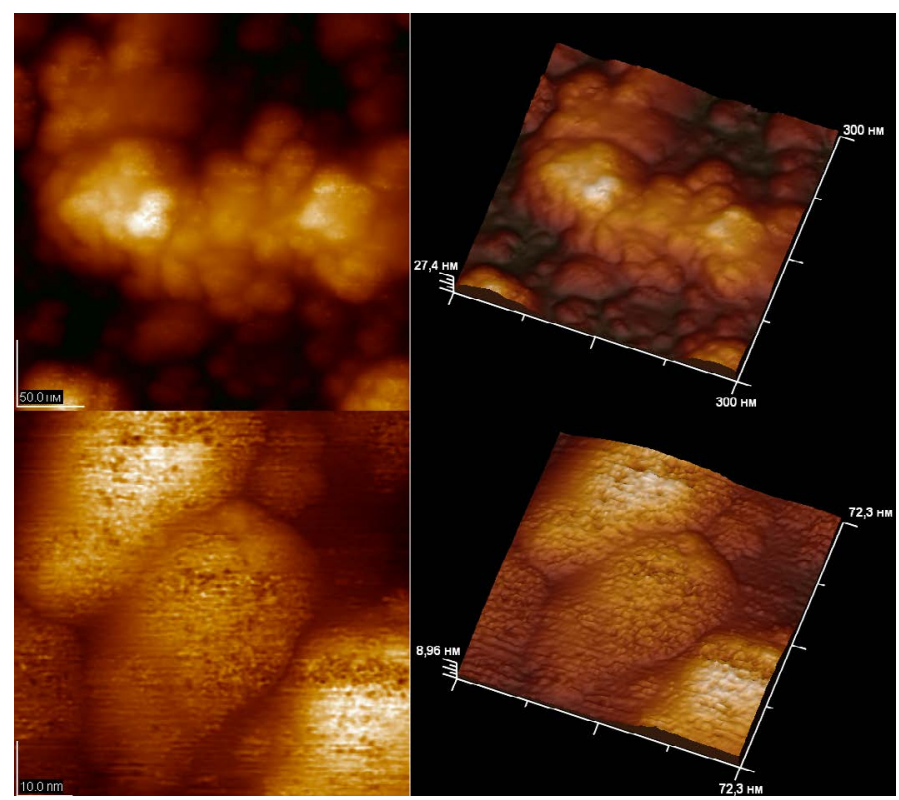

Figure 22. Virions of AMV on the (111) surface of silicon when a fresh suspension virion is applied eliminated. Chemical adsorption has also to be excluded, since silicon does not form chemical bonds with any component of viral capsids. Therefore, the most probable processes in the adsorption of virions on the (111) surface silicon are van der Waals interactions and creation of hydrogen bonds with the surface. Van der Waals interactions dominate for adsorption of virions on the surface of graphite. This material has strong developed hydrophobic properties. That is why the formation of stronger hydrogen bonds turns out impossible. The energy of Van der Waals interactions is the lowest $(\sim 2 \mathrm{~kJ})$ among others. Therefore the Van der Waals interactions are very weak and are not accompanied by significant changes in the conformation of the molecules. As a result, there is no change in the height of the TMV virions on the surface of graphite.

On the contrary, the adsorption of TMV virions on the (111) surface of silicon, is accompanied by significant changes in virions conformation and a decrease in the height of the virions to $11.7 \mathrm{~nm}$ was clearly established. An identical result was obtained in the study of the behavior of alfalfa mosaic virus (AMV) on the surface with the same geometry. Adsorption of AMV virions was accompanied by a decrease in their height from $19.0 \mathrm{~nm}$ to $9.0 \mathrm{~nm}$.

It is obvious that such changes in the conformation of the virions are due to the amino acid composition of the outer surface of the capsid. As the negatively charged amino acid residues containing hydroxyl and carboxyl groups (serine, threonine, tyrosine, asparagine and glutamic acid) are concentrated on the outer surface, they can provide virion adhesion by forming hydrogen bonds with the surface. By comparing amino acid content of the side chains of the above enumerated groups, that is in capsid proteins AMV and TMV (AMV-CP and TMV-CP, respectively), one comes to conclusion that content of such amino acids in AMV-CP is greater Table 1.

Thus, adsorption of the tobacco mosaic virus and alfalfa mosaic virus on the surface of $\mathrm{Si}$ (111) is accompanied by variations in accommodation of the virions due to formation of hydrogen bonds and van der Waals interactions. The change in accommodation concludes in reducing of the virions height due to the interaction of amino acid residues on the outer surface of the capsid with silicon atoms on the surface of $\mathrm{Si}$ (111). The adsorption of TMV virions is accompanied by appearance of mono-layer films, while multi virion layers observe if the adsorption of TMVs on the surface of Si (111) occurs.

Investigation of the suspension of AMV virions and complexes of antybodies on the surface of $\mathrm{Si}$ (111) showed that the antibodies are specifically linked on the surface of the AMV virions (Figure 23). This binding is accompanied by the aggregation of virions in dense agglomerations and reduction in their height from $19 \mathrm{~nm}$ to $9 \mathrm{~nm}$. In the appointed case, predominant formation of multilayer disordered clusters of virions has taken place. Consequently, the binding of antibodies prevents the aggregation of virions. The suggestion can be confirmed by the specific distribution of virions on the Si (111) surface and decrease in the height of the viral particles clearly visible in the picture.

\section{Conclusion}

Nanowires of different types were synthesed and investigation of their physical, physico-chemical properties and morphology by applying probe microscopy and atomic resolution spectroscopy has been carried out. It is confirmed that the geometry of VTM's particles can be controlled by special preparing and dirigible alternation of chemical and mechanic environment parameters. The optical activity of the TMV-Au complex with the maximum on wavelength $540 \mathrm{~nm}$ 

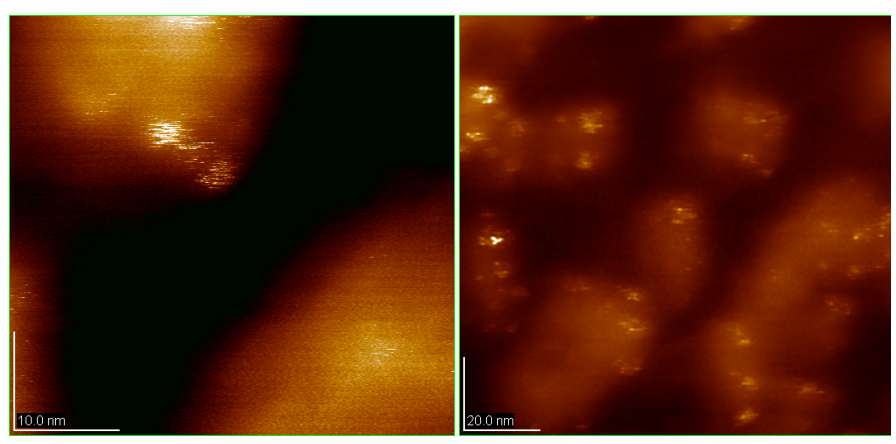

Figure 23. Suspensions of AMV virions and antibody complexes on the (111) surface of silicon

is detected. The dependence of the optical absorption spectra intensity on the orientation of the polarization vector is observed. Established circular dichroism, opens up the possibility to use the TMV-Au complexes for smart materials creation.

In the study of nanowires electronic properties by the method of probe tunneling spectroscopy, it has been found that spontaneous and induced transitions to a state with relatively high electrical conductivity take place in the voltage tension from 0 to 6 Volts. To our knowledge this effect is not observed for pure TMVs. In connection with the VTM's shell genetic programming, Tobacco Mosaic Virus derivatives can be manufactured with increased selectivity to inorganic materials or substrates. The latter fact allows us to obtain efficient self-assemblies of nanosized biostructures for many functional microdevices. As it has been proved aggregation and clusterization of composite nanoparticles due to interaction of plant viruses with antibodies are absent.

However, superficial destroying of gold is observed if the TMV's nanoparticles have been removed from gold surface.

The proposed method for the synthesis of nanowires represents perspectives for significant improvement of useful technologies for production nanomaterials based on plant viruses. Knowing to combine TMV with inorganic and organic materials traces the route for developing a wide scale of interesting composites and hybrid materials like those which have been discussed here. Beside it TMV's templates manifest such level of reliability that allows to explore them under so hard conditions that ultra pass capabilities of traditionally used biological molecules.

\section{References}

1. Sarikaya M, Tamerler C, Jen AK, Schulten K, Baneyx F (2003) Molecular biomimetics: nanotechnology through biology. Nat Mater 2: 577-585. [Crossref]

2. Kordas K, Pap AE, Vahakangas J, Uusimaki A, Leppavuori S (2005) Carbon nanotube synthesis on oxidized porous silicon. Appl Surf Sci 252: 1471.

3. Wang JH, Su PY, Lu MY, Chen LJ, Chen CH, et al. (2007) Synthesis of Cu Nanotubes with Silicon Oxide Nanowire Templates by MOCVD. Electrochem Solid-State Lett 8: 9 .

4. Sun S, Yang D, Zhang G, Sacher E, Dodelet JP (2007) Synthesis and Characterization of Platinum Nanowire-Carbon Nanotube Heterostructures. Chem Mater 19: 6376.

5. Xiang B, Wang P, Zhang X, Dayeh SA, Aplin DP, et al. (2007) Rational synthesis of p-type zinc oxide nanowire arrays using simple chemical vapor deposition. Nano Lett 7: 323-328. [Crossref]

6. Durrer L, Helbling Z, Zenger C, Jungen A, Stampfer C, et al. (2008) SWTN growth by CVD on Ferritin-based iron catalyst nanoparticles towards CNT sensors. Sens Actuators B 132: 485-490.

7. Zhang D, Yang J, Li Y (2013) Spectroscopic characterization of the chiral structure of individual single-walled carbon nanotubes and the edge structure of isolated graphene nanoribbons. Small 9: 1284-1304. [Crossref]
8. Feng X, Shankar K, Varghese OK, Paulose M, Latempa TJ, et al. (2008) Vertically aligned single crystal $\mathrm{TiO} 2$ nanowire arrays grown directly on transparent conducting oxide coated glass: synthesis details and applications. Nano Lett 8: 3781-3786. [Crossref]

9. Ghoshal T, Biswas S, Kar S, Dev A, Chakrabarti S, et al. (2008) Direct synthesis of ZnO nanowire arrays on $\mathrm{Zn}$ foil by a simple thermal evaporation process. Nanotechnology 19: 065606. [Crossref]

10. Karbivskiy VL, Korniyuk TA (2009) Ukrainica Bioorganica Acta 2: 7.

11. Dengand Z, Mao C (2003) Nano Lett 3: 1545.

12. Ma Y, Zhang J, Zhang G, He H (2004) Polyaniline nanowires on Si surfaces fabricated with DNA templates. J Am Chem Soc 126: 7097-7101. [Crossref]

13. Hashimoto Y, Matsuo Y, Ijiro K (2005) Chem Lett 34: 112.

14. Gu Q, Cheng C, Gonela T, Suryanarayanan S, Anabathula S, et al. (2006) Nanotechnology 17: R14.

15. Kudo H, Fujihira M (2006) IEEETrans Nanotechnol 5: 90.

16. Kinsella JM, Ivanisevic A (2007) DNA-templated magnetic nanowires with different compositions: fabrication and analysis. Langmuir 23: 3886-3890. [Crossref]

17. Reches M, Gazit E (2003) Casting metal nanowires within discrete self-assembled peptide nanotubes. Science 300: 625-627. [Crossref]

18. Zhang B, Davis SA, Mendelson NH, Mann S (2000) Bacterial templating of zeolite fibres with hierarchical structure. Chem Commun 2000: 781-782.

19. Mogul R, Kelly JJG, Cable ML, Hebard AF (2005) Synthesis and magnetic characterization of microstructures prepared from microbial templates of differing morphology. Mater Lett 60: 19.

20. Liang X, Liu J, Li S, Mei Y, Yanqing W (2008) Magnetic and mechanical properties of micro/nano particles prepared by metallizing rod-shaped bacteria. Mater Lett 62: 2999-3002.

21. Kumara MT, Tripp BC, Muralidharan S (2007) Dielectric Saturation of the Ion Hydration Shell and Interaction between Two Double Helices of DNA in Mono- and Multivalent Electrolyte Solutions: Foundations of the $\varepsilon$-Modified Poisson-Boltzmann Theory. J Phys Chem C 111: 5264-5276.

22. Evans DJ (2008) The bionanoscience of plant viruses: templates and synthons for new materials. J Mater Chem 18: 3746-3754.

23. Namba K, Pattanayek R, Stubbs G (1989) Visualization of protein-nucleic acid interactions in a virus. Refined structure of intact tobacco mosaic virus at $2.9 \mathrm{~A}$ resolution by X-ray fiber diffraction. $J$ Mol Biol 208: 307-325. [Crossref]

24. Pattanayek R, Stubbs G (1992) Structure of the U2 strain of tobacco mosaic virus refined at 3.5 A resolution using X-ray fiber diffraction. $J$ Mol Biol 228: 516-528. [Crossref]

25. Wang H, Stubbs G (1994) Structure determin ation of cucumber green mottle mosaic virus by X-ray fiber diffraction. Significance for the evolution of tobamoviruses. J Mol Biol 239: 371-384. [Crossref]

26. Wang H, Culver JN, Stubbs G (1997) Structure of ribgrass mosaic virus at $2.9 \mathrm{~A}$ resolution: evolution and taxonomy of tobamoviruses. J Mol Biol 269: 769-779. [Crossref]

27. Durham AC, Finch JT, Klug A (1971) States of aggregation of tobacco mosaic virus protein. Nat New Biol 229: 37-42. [Crossref]

28. Dawson WO, Beck DL, Knorr DA, Grantham GL (1986) cDNA cloning of the complete genome of tobacco mosaic virus and production of infectious transcripts. Proc Natl Acad Sci U S A 83: 1832-1836. [Crossref]

29. Culver JN, Dawson WO, Plonk K, Stubbs G (1995) Site-directed mutagenesis confirms the involvement of carboxylate groups in the disassembly of tobacco mosaic virus. Virology 206: 724-730. [Crossref]

30. Culver JN (2002) Tobacco mosaic virus assembly and disassembly: determinants in pathogenicity and resistance. Annu Rev Phytopathol 40: 287-308. [Crossref]

31. Gerasopoulos K, McCarthy M, Banerjee P, Fan X, Culver JN, et al. (2010) Biofabrication methods for the patterned assembly and synthesis of viral nanotemplates. Nanotechnology 21: 055304. [Crossref]

32. Royston E, Lee SY, Culver JN, Harris MT (2006) Characterization of silica-coated tobacco mosaic virus. $J$ Colloid Interface Sci 298: 706-712. [Crossref] 
33. Yi H, Nisar S, Lee SY, Powers MA, Bentley WE, et al. (2005) Patterned assembly of genetically modified viral nanotemplates via nucleic acid hybridization. Nano Lett 5: 1931-1936. [Crossref]

34. Gerasopoulos K, Chen X, Culver J, Wang C, Ghodssi R (2010) Self-assembled Ni/TiO2 nanocomposite anodes synthesized via electroless plating and atomic layer deposition on biological scaffolds. Chem Commun 46: 7349-7351.

35. Gerasopoulos K, McCarthy M, Royston E, Culver JN, Ghodssi R (2008) Nanostructured nickel electrodes using the Tobacco mosaic virus for microbattery applications. $J$ Micromech. Microeng 18: 104003.

36. Niu Z, Liu J, Lee LA, Bruckman MA, Zhao D, et al. (2007) Biological templated synthesis of water-soluble conductive polymeric nanowires. Nano Lett 7: 3729-3733. [Crossref]

37. Jung-Sun Lim (2010) Formation of Au/Pd Alloy Nanoparticles on TMV. Journal of Nanomaterials 4: 620505.

38. Dujardin E (2003) Nano Letters 3: 413.

39. Correa-Duarte MA, Pérez-Juste J, Sánchez-Iglesias A, Giersig M, Liz-Marzán LM (2005) Aligning Au nanorods by using carbon nanotubes as templates. Angew Chem Int Ed Engl 44: 4375-4378. [Crossref]

40. Wang H, Lin W, Fritz KP, Scholes GD, Winnik MA, et al. (2007) Cylindrical block co-micelles with spatially selective functionalization by nanoparticles. J Am Chem Soc 129: 12924-12925. [Crossref]

41. Bromley KM (2008) Preparation of highquality nanowires by tobacco mosaic virus templating of gold nanoparticles. J Mater Chem 18: 4796.

42. Fang J (2004) Ency of Nanoscience \& Nanotechnology 5: 3953.

43. Zhang LY (2009) Synthesis of Ni nanowires via a hydrazine reduction route in aqueous ethanol solutions assisted by external magnetic fields. Nano-Micro Letters 1: 49-52.
44. Tseng TC, Urban C, Wang Y, Otero R, Tait SL, et al. (2010) Charge-transfer-induced structural rearrangements at both sides of organic/metal interfaces. Nat Chem 2: 374379. [Crossref]

45. Knez M, Sumser M, Bittner AM, Wege C, Jeske H, et al. (204) Adv Funct Mater 14: 116

46. Royston E, Ghosh A, Kofinas P, Harris MT, Culver JN (2008) Self-assembly of virusstructured high surface area nanomaterials and their application as battery electrodes. Langmuir 24: 906-912. [Crossref]

47. Manocchi AK, Seifert S, Lee B, Yi H (2010) On the thermal stability of surfaceassembled viral-metal nanoparticle complexes. Langmuir 26: 7516-7522. [Crossref]

48. Knez M, Kadri A, Wege C, Gosele U, Jeske H, et al. (2006) Atomic layer deposition on biological macromolecules: metal oxide coating of tobacco mosaic virus and ferritin. Nano Lett 6: 1172-1177. [Crossref]

49. Atanasova P, Rothenstein D, Schneider JJ, Hoffmann RC, Dilfer S, et al. (2011) Virustemplated synthesis of $\mathrm{ZnO}$ nanostructures and formation of field-effect transistors. $A d v$ Mater 23: 4918-4922. [Crossref]

50. Bruckman MA, Soto CM, McDowell H, Liu JL, Ratna BR, et al. (2011) Role of hexahistidine in directed nanoassemblies of tobacco mosaic virus coat protein. ACS Nano 5: 1606-1616. [Crossref]

51. Wargacki SP, Pate B, Vaia RA (2008) Fabrication of 2D ordered films of tobacco mosaic virus (TMV): processing morphology correlations for convective assembly. Langmuir 24: 5439-5444. [Crossref]

52. Mueller A, Eber FJ, Azucena C, Petershans A, Bittner AM, et al. (2011) Inducible site-selective bottom-up assembly of virus-derived nanotube arrays on RNA-equipped wafers. ACS Nano 5: 4512-4520. [Crossref]

53. Circular dichroism: principles and applications, 2nd Ed., Edt. N. Berova, K. Nakanishi, and R. W. Woody (Wiley-VCH, N.Y., 2000).

Copyright: (C2018 Kasiyanenko VKH. This is an open-access article distributed under the terms of the Creative Commons Attribution License, which permits unrestricted use, distribution, and reproduction in any medium, provided the original author and source are credited. 